\title{
Increasing the benefits of eye-tracking devices in divided visual field studies of cerebral asymmetry
}

\author{
GEOFFREY R. PATCHING and TIMOTHY R. JORDAN \\ University of St. Andrews, St. Andrews, Scotland
}

\begin{abstract}
A wide range of methods has been proposed for ensuring central fixation in divided visual field studies of cerebral asymmetry. We present some of the problems associated with ensuring central fixation and argue that objectively monitoring fixation location with an eye-tracking device can provide the only accurate and, therefore, acceptable technique. However, the mere use of this equipment does not overcome all of the problems associated with controlling fixation location, and previous studies have overlooked the importance of providing feedback on fixation accuracy and the role of visual attention. We propose a straightforward method of accommodating both these influences in studies using eyetracking devices to control fixation location.
\end{abstract}

Anatomically, the arrangement of the human visual system is such that nerve fibers carrying information about stimuli falling in the left visual hemifield (LVF) project to the right lateral geniculate nucleus (LGN) and thence to the visual cortex of the right cerebral hemisphere, whereas fibers carrying information about stimuli falling in the right visual hemifield (RVF) project to the left LGN and thence to the visual cortex of the left cerebral hemisphere. Thus, provided that a person's point of fixation can be accurately determined and provided stimulus presentations are sufficiently brief to prevent the eye movements necessary to bring these stimuli into foveal vision, stimuli can be projected in whichever visual hemifield (and, therefore, to whichever cerebral hemisphere) is chosen by the experimenter. Differences in the speed or accuracy with which information in each visual hemifield is processed should arise when one hemisphere is superior to the other in processing that information (see, e.g., Kimura, 1961).

However, great care needs to be taken to ensure that effects produced by underlying cerebral processing asymmetry are not contaminated by artifacts. Visual acuity drops rapidly from the fovea to the periphery (see, e.g., Anstis, 1974). Moreover, the anatomical arrangement of the retina and visual system indicates that there is an overlap at the midline of at least $1^{\circ}$, where information falling on the retina will pass to both hemispheres (see, e.g., Bunt \& Minckler, 1977). Thus, before accurate inferences can be made about the processing of stimuli by the two cerebral hemispheres, researchers must ensure that subjects are fixating centrally, so that stimuli presented to the left or right hemiretina of each eye have the same degree of

This research was funded in part by a University of St. Andrews Research Award. Correspondence concerning this article should be sent to G. R. Patching, Department of Psychology, University of York, Heslington, York, YO1 5DD England (e-mail: gp106@york.ac.uk) or Timothy Jordan, Department of Psychology, University of Nottingham, University Park. Nottingham, NG7 2RD England (e-mail: trj@psych. nott.ack.uk). retinal eccentricity. Without this control, stimuli may be projected to the wrong cerebral hemisphere or to both cerebral hemispheres, or they may enjoy a perceptual advantage over stimuli presented in the other visual hemifield simply because of differences in retinal acuity rather than underlying cerebral processing asymmetry.

\section{Techniques for Ensuring Central Fixation}

Although the importance of ensuring central fixation is widely acknowledged (see, e.g., Bradshaw \& Nettleton, 1983; Hellige \& Sergent, 1986; Maddess, Rosenblood, \& Goldwater, 1973; McKeever \& Huling, 1971), much less agreement exists over the way that this can be ensured. The purpose of this paper is to underscore the critical potential offered by eye-tracking equipment for ensuring central fixation, to discuss the role of visual attention and feedback, and to present a simple method by which visual attention and feedback can be accommodated to increase the control offered by eye-tracking equipment. However, in order to place this technique in perspective, it is necessary to review other methods that have previously been proposed to control central fixation.

Emphasized instructions. One of the most popular methods for controlling fixation location is to simply instruct subjects to fixate centrally (see, e.g., Eng \& Hellige, 1994; Eviatar \& Zaidel, 1991; Faust, Kravetz, \& Babkoff, 1993; Kitterle, Christman, \& Conesa, 1993; Koenig, Wetzel, \& Caramazza, 1992). However, although subjects may attempt to comply with emphasized instruction, a number of studies indicate that emphasized instructions alone fail to ensure that central fixation occurs on every trial (e.g., Batt, Underwood, \& Bryden, 1995; Findlay \& Kapoula, 1992; Jones \& Santi, 1978; Jordan, Patching, \& Milner, 1998a; Terrace, 1959). For example, Batt et al. required subjects to identify words presented in the left or right visual field while eye position was monitored using the reflection of an infrared beam from the cornea of the right eye. Despite instructions to fixate centrally, Batt et al. found that subjects fixated more than $1^{\circ}$ away 
from the required point of fixation on $14 \%$ (Experiment 1 ) and $17 \%$ (Experiment 2 ) of the trials. More recently, Jordan et al. (1998a) examined the traditional RVF advantage for words presented to the LVF or RVF while fixation location was monitored using infrared reflection from the cornea of the right eye. Despite emphasized instructions to fixate centrally, up to $70 \%$ of fixations were not central, with more fixations falling to the right than to the left of the central fixation point. Moreover, even experienced subjects fail to maintain central fixation following emphasized instructions. For example, Findlay and Kapoula (1992) investigated perception of laterally displaced targets, using a highly precise scleral search coil device and experienced subjects (including the authors). They found that, despite instructions to maintain central fixation until the target appeared, eye position at the start of each trial was displaced on an appreciable number of trials. Indeed, they report that $30 \%$ of their data had to be discarded as a result of fixation displacements falling more than $1^{\circ}$ from central. Furthermore, even after discarding these trials, fixation location was still found to be biased, on average, $0.38^{\circ}$ to the right of central. The indication of these studies is, therefore, that the use of instructions alone fails to ensure central fixation on every trial, even with experienced, highly motivated subjects.

Secondary tasks. Recognizing the need to provide subjects with further encouragement to fixate centrally, a number of researchers have used the indirect method of briefly presenting a single stimulus centrally, prior to or simultaneously with lateralized targets. Subjects are required to identify the central stimulus along with the lateralized targets on each trial (see, e.g., Boles, 1983, 1985; Hellige, Taylor, \& Eng, 1989; Luh \& Levy, 1995; McKeever \& Huling, 1971; Wagner \& Harris, 1994). The logic underlying this approach is that, unless subjects are fixating centrally at the time of target presentation, they will be unable to report the centrally presented stimulus correctly. Trials in which subjects cannot report the centrally presented stimulus correctly are rejected or re-presented at a later stage (for an example of this procedure, see McKeever \& Huling, 1971). However, there are two major disadvantages with this technique, either of which could affect performance with target stimuli.

First, the efficacy with which this method can ensure central fixation is questionable. In particular, the physical parameters of any centrally presented stimulus must be such that any shift in fixation leads to an incorrect report of the fixation stimulus. The ability to identify stimuli is likely to differ between subjects and throughout the experimental session as subjects become more practiced with the task (see, e.g., Wolford, Marchak, \& Hughes, 1988). Attempts can be made to accommodate practice effects and the differential ability of subjects to identify stimuli by manipulating the luminance or presentation time of fixation stimuli independently of lateralized targets (see, e.g.,
Boles, 1983, 1985). However, even if one assumes that accurate report of fixation stimuli reflects the perceptibility of each fixated stimulus and not a correct guess of a noncentrally fixated stimulus, any changes made to the presentation parameters of centrally presented stimuli must be made retrospectively, on the basis of performance from previous trials. Consequently, even if attempts are made to determine the threshold of stimulus identification individually for each subject and throughout the experimental session, a subject may still make a substantial number of noncentral fixations that can contaminate the experimental task with shifts in retinal eccentricity.

Second, the use of a secondary, fixation task may interfere with the primary, experimental task (Hellige \& Sergent, 1986), especially if the two tasks have overlapping cognitive demands. Hines (1972) was one of the first to raise this concern, which was later reiterated by Carter and Kinsbourne (1979), who found that a centrally presented digit interfered with an experimental task in children. Other, arguably less interfering stimuli, such as arrowheads, have been used to indicate order of stimulus report (see, e.g., Kim, 1996; Schmuller \& Goodman, 1979). Although these tasks may be less likely to interfere with the processing of the experimental task, however, our earlier arguments concerning the identification of stimuli from noncentral fixations still apply.

The possibility of interference between alphanumeric fixation stimuli and the experimental task has been widely acknowledged (see, e.g., Hellige \& Sergent, 1986; McKeever \& Huling, 1971; Young \& Ellis, 1985). In an attempt to overcome the interfering effect that a centrally presented alphanumeric stimulus may have on the experimental task, Young and Ellis included separate, randomly determined trials on which a single stimulus was presented centrally rather than laterally. The rationale behind this approach was that, if subjects were fixating centrally throughout the experiment, central stimuli should produce better performance than lateral stimuli. However, better performance with central stimuli does not necessarily indicate central fixation. For example, fixating slightly to one side of center may still produce greater report accuracy for central stimuli over lateral stimuli, while still inspiring an artifactual influence on performance with laterally presented targets.

Watching subjects' eyes. More direct methods overcome some (but not all) of the problems associated with emphasized instructions and the use of a secondary report task. One such method is to have an observer watch subjects' eyes. Trials on which, in the opinion of the observer, subjects were not fixating centrally are rejected or re-presented at a later time (see, e.g., Berlucchi, Tassinari, Marzi, \& Di Stefano, 1989; Maddess et al., 1973; Mohr, Pulvermüller, \& Zaidel, 1994; Nicholls \& Atkinson, 1993; Schwartz, Montagner, \& Kirsner, 1987). For example, Maddess et al. described a method in which fixation location could be monitored by watching subjects' eyes through a monocular lens, whereas Berlucchi 
et al. used video camera to project an image of subjects' eyes onto a television screen by which fixation location could be monitored. However, an observer's assessment of central fixation may be affected by a number of unwanted influences, not least by the experimental hypothesis, levels of vigilance, and even inaccurate perception of fixation location. Without knowing that observers provide consistent accurate assessment of fixation location, it is impossible to be confident that this procedure ensures that subjects fixate centrally on every trial.

In sum, confidence that subjects are fixating centrally at the time of lateralized target presentation cannot be high when methods such as emphasized instructions, a secondary fixation task, or watching subjects' eyes are used to assess fixation location.

Objectively monitoring fixation location. To overcome the problems associated with other techniques, a number of researchers have used eye-tracking equipment to objectively ensure central fixation (e.g., Chiarello, Dronkers, \& Hardyck, 1984; Christman, 1990; Hardyck, Chiarello, Dronkers, \& Simpson, 1985; Jordan, Patching, \& Milner, 1998a, 1998b; Patching, Jordan, \& Milner, 1998). For example, Hardyck et al. were among the first to use eye-tracking equipment to control the onset of stimulus presentation. Presentation of trials was controlled by a computer interfaced with an eye tracker, and stimuli were presented only when $x$ - and $y$-coordinates returned from the eye tracker fell within a prespecified range for five successive samples. Provided care is taken to calibrate these devices accurately (Beauvillain \& Beauvillain, 1995), the use of eye-tracking equipment provides an objective and effective method of ensuring central fixation. However, the mere use of eye-tracking equipment does not overcome all the problems associated with ensuring central fixation, and further consideration of the psychological processes involved can help increase the validity and extent of control offered by these devices.

\section{Provision of Feedback}

It has been known for some years that subjects are often unaware of their precise point of fixation (see, e.g., Brindley \& Merton, 1960). Thus, when fixation location is monitored with an eye-tracking device and target presentation is withheld until subjects are accurately fixating the required location, subjects may often fixate incorrectly and make several attempts at fixating the required location before central fixation is achieved and maintained. However, Steinman (1977) noted that subjects' ability to fixate a predetermined location is considerably increased when they are provided with feedback about their fixation location. Indeed, we have found in our own laboratory that when little or no feedback about fixation location is provided, subjects are uncertain that they are fixating the required location and often develop a hunting strategy whereby a series of adjustments are made around the point of fixation in the hope that such adjustments will eventually result in accurate fixation of the required location. More im- portantly, these adjustments can continue even when central fixation has occurred and target presentation is taking place. Without feedback to inform subjects they are fixating centrally, target presentation may be unexpected and may take place while subjects are still making adjustments to their eye position. In short, feedback about fixation location minimizes the reliance placed on subjects' abilities to monitor their fixation location and minimizes the risk that fixation will be shifted at the time of target presentation. Unfortunately, previous studies using eye-tracking devices have provided little or no feedback about fixation location prior to target presentation.

\section{A Role for Visual Attention}

The relationship between attention and fixation has attracted the interest of researchers for many years. In particular, it is possible that differences in performance between the visual fields results from a tendency to attend more to one visual field than to the other (see, e.g., Bryden, 1980; see also Hardyck et al., 1985, for a review). Indeed, as early as 1866 , Helmholtz (1866/1925) published a series of observations in which he remarked that he could direct his attention to regions of the visual field away from the point of fixation, and Wundt (1912) commented on the ability to separate the line of fixation from the line of attention.

More recently, a number of studies have investigated the link between fixation and attention by measuring the time it takes to make saccadic eye movements to a peripheral target when (1) there is a gap between the offset of the fixation point and the onset of the target, (2) there is no gap between the offset of the fixation point and the onset of the target, or (3) the target is presented while the fixation point remains on (Fischer, 1986; Mackeben \& Nakayama, 1993; Reuter-Lorenz, Hughes, \& Fendrich, 1991; Sheliga, Kuznetsov, \& Shul'govskii, 1991). Typically, findings in this area indicate that saccadic eye movements are much faster (express saccades, defined by their extremely short reaction times of 75-100 $\mathrm{msec}$ ) when there is a gap between the offset of the fixation point and the onset of the target than when there is no gap between fixation point offset and target onset or when the fixation point remains on while the target is presented. Since express saccades can occur so rapidly, and since many lateralized stimuli are presented for longer than 75 msec (see, e.g., Hardyck et al., 1985; Kitterle et al., 1993; Koenig et al., 1992; Lukatela, Carello, Savic, \& Turvey, 1986; Tramer, Butler, \& Mewhort, 1985), express saccades are a potentially confounding factor in divided visual field studies of cerebral processing asymmetry. However, Fischer and Breitmeyer (1987), summarizing data on the initiation of saccadic eye movements in relation to the mechanisms of visual attention, argued that express saccades do not occur when subjects are attending a fixation point (i.e., when there is no gap between the offset of the fixation point and the onset of the target). From this review, they concluded that visual 
attention can be in two states - engaged or disengaged-and that, during engaged visual attention, saccades are inhibited, providing steady fixation. Thus, in view of the evidence that express saccades are suppressed when visual attention is engaged, confounding influences of express saccades in studies of visual field asymmetry should be inhibited when subjects attend the fixation point.

From the findings of Yantis and Jonides (1984) and Jonides and Yantis (1988), one way of ensuring that subjects attend the fixation point (rather than merely fixate it) is to use fixation points with abrupt onsets. For example, Yantis and Jonides presented displays that contained one item with an abrupt onset embedded among several other items. When the onset item was the target, variations in the size of the display had little effect on target performance, indicating that when an item in the visual field has an abrupt onset, attentional resources rapidly shift to the location of this item, to the exclusion of other locations in the visual field (Jonides \& Yantis, 1988; Yantis \& Jonides, 1984).

The argument being developed, therefore, is that studies of lateralized target performance that require central fixation would benefit considerably from the use of feedback about fixation location and from the use of fixation points with abrupt onsets that permit control over visual attention. Here, we present a simple technique that accommodates both these influences.

\section{METHOD}

\section{Fixation Stimulus}

In order to avoid interference between the fixation stimulus and the experimental task, a single but clearly visible pixel was used as a central fixation point on each trial. To engage visual attention, the fixation point was composed of a series of abrupt onsets, which was achieved by making the central fixation point pulse on and off. The pulsating fixation point also provided the means by which subjects were supplied with feedback about their fixation location. This was achieved by changing the pulse rate of the fixation point when steady central fixation occurred, as indicated by the values returned from the eye-tracking device (see the Fixation Display section).

\section{Apparatus}

The position of each eye was monitored, using an infrared ACS Applied Research Developments EM 130 eye monitor that operates by emitting low levels of (invisible) infrared light into each eye and detecting changes in the angle at which this light is reflected. The monitor was fixed directly onto the head of each subject and had emitter and sensor leads that could be positioned a very short distance $(10 \mathrm{~mm})$ from subjects' eyes. The head of each subject was clamped in a head brace throughout each experiment to prevent head movement. Pretesting showed that this combination of head clamping, eye-monitor clamping, and proximal emitters and sensors allowed accurate and consistent measurement of fixation location to within $7.5 \mathrm{~min}$ of arc. Specifically, repeatedly calibrating the tracker at the start of the study enabled us to map digital output to amount of shift in fixation from center. Thus, we knew what digital value must be exceeded for a fixation shift of $7.5 \mathrm{~min}$ of arc from center to be exceeded. Moreover, by fixating different locations, we could reliably alter the output of the tracker by constant amounts to within our $7.5-\mathrm{min}$ limits. Under these conditions, fixation at any predetermined location was denoted by a 1,000 -msec period during which output from the tracker never exceeded the digital value corresponding to $7.5 \mathrm{~min}$ of arc away from that location, indicating that the tracker's output was stable and that fixations were accurate to within our 7.5-min limits. The output of the eye monitor was recorded through the ADC input of a Cambridge Research Systems D300 intelligent interface that also controlled each visual display. Input conversion time was approximately $25 \mu \mathrm{sec}$.

Stimuli were plotted on a Hewlett-Packard 1340A oscilloscope equipped with rapid decay phosphor with a spot persistence time of $10 \mu \mathrm{sec}$ to $10 \%$. The oscilloscope had been modified to enable precise control over the visual angle of stimuli and to provide a higher resolution display (Jordan \& Martin, 1987). The experiment was conducted in a darkened booth, and the subjects entered their responses by way of two keys interfaced with the computer.

\section{Fixation Display}

At the start of each trial, the small pulsating fixation point was presented at the required (central) point of fixation. The pulse rate was sufficiently low as to ensure that onset with each pulse was abrupt (thus capturing visual attention) and not diluted by the persistence (visual or phosphor) of the previous pulse. In our tests, an on-time of approximately $100 \mathrm{msec}$, with an offset-onset interval of $100 \mathrm{msec}$, worked best with a P4 phosphor. Phosphors with slower decay rates (e.g., P31) may require a greater offset-onset interval, although the use of slower phosphors may incur other problems (see, e.g., Groner, Groner, Muller, Bischof, \& Di Lollo, 1993). The fixation point continued to pulse until the subjects fixated centrally for 1,000 msec. $^{1}$

As soon as continuous central fixation occurred, the puise rate increased (on-time of approximately $50 \mathrm{msec}$ and offset-onset interval of $50 \mathrm{msec}$ ), informing the subjects that central fixation was occurring and that the next target was ready for presentation. However, this feedback was achieved while still maintaining the presence of abrupt onsets necessary to capture visual attention. If subjects shifted their fixation before target presentation took place, target presentation was immediately inhibited, and the fixation point resumed its original (lower) pulse rate until central fixation again occurred for $1,000 \mathrm{msec}$. All buttonpresses were disabled (thus preventing target presentation) until continuous central fixation occurred (as signaled to the subject by the increased pulse rate of the fixation point), at which time input buffers for buttonpresses were flushed to ensure that only a buttonpress made while centrally fixating could initiate a target display. The subjects initiated each target presentation with a buttonpress because this helped the subjects feel in control of the task and enabled them to prepare for each target presentation.

We decided to conduct a simple experiment using this procedure to examine the efficacy of employing a pulsating fixation point to provide feedback and engage visual attention. This was achieved in an experiment designed to replicate the often-reported advantage for words presented in the RVF over words presented in the LVF (see, e.g., Bradshaw \& Nettleton, 1983, for a review).

Subjects. Sixteen paid undergraduate students from the University of St. Andrews participated in the experiment. All the subjects reported normal (i.e., not corrected-to-normal) vision, were native speakers of English, and were classified as right-handed by selfreport and by administration of a revised version of the 12-item Annett Handedness Inventory (Annett, 1967).

\section{Stimuli}

Testing was achieved using a two-alternative forced-choice procedure (see, e.g., Johnston, 1978; Jordan \& Bevan, 1996; Reicher, 1969), which had previously revealed strong RVF advantages for words in lateralization experiments (see, e.g., Jordan et al., 1998a, 1998b; Reuter-Lorenz \& Baynes, 1992). To this end, 96 four-letter 
words were selected as experimental stimuli, with a mean frequency of written occurrence of 222 per million (Carroll, Davies, \& Richman, 1971). Two groups of 96 stimuli were formed from pseudorandom selections of the word stimuli, with each group containing one member of each matched word pair. In addition, a further 96 matched pairs of four-letter words were constructed to provide 96 practice stimuli at the beginning of each session. Each word target was followed by a pattern mask that permitted the use of high-contrast stimuli while maintaining overall performance at a meaningful level. Each lateralized target-mask display was preceded by the central fixation point described earlier.

\section{Visual Conditions}

Stimuli were presented so that the innermost edge of each word was $2^{\circ}$ to either the left (LVF) or right (RVF) of the fixation point. A single letter $x$ subtended a horizontal visual angle of approximately $0.20^{\circ}$. Four proportionally spaced letter $x$ s subtended a horizontal visual angle of approximately $1.10^{\circ}$. Each mask subtended a vertical visual angle of approximately $0.50^{\circ}$ and a horizontal visual angle that matched that of each word target. The experiment was conducted in a darkened booth, and the subjects entered their responses via two illuminated keys interfaced with the computer.

\section{Design}

The subjects took part in one 50-min session. Each word target was presented once in each visual hemifield, in a pseudo andom order that prevented the subjects from correctly anticipating stimulus location. Each session was divided into three sections (practice, $A$, and $B$ ), with no obvious transition from one section to the next. Each of the two presentations of each word (LVF, RVF) occurred in a different section ( $A$ or $B$ ), to ensure that the same word was not seen in close succession in the left and right visual hemifields. The allocation of stimuli to sections $A$ and $B$ was rerandomized for each subject.

\section{Calibration}

The eye-tracking equipment was calibrated for each subject at the start of the session by presenting one small but clearly visible pixel at a series of unpredictable horizontal distances (up to $3^{\circ}$ ), left and right, from a central pixel (the central fixation point). The subjects were instructed to fixate each noncentral pixel while the output from the eye-tracking equipment was monitored and adjusted such that a change in eye position registered an equivalent change in the value returned from the eye tracking device. This calibration procedure has considerable empirical support and is widely used in eye movement research (e.g., Beauvillain \& Beauvillain, 1995; Briihl \& Inhoff, 1995; Eden, Stein, Wood, \& Wood, 1994; Inhoff, 1989; Jones \& Santi, 1978; Rayner \& Inhoff, 1981). Calibration continued until the numerical values returned from the eye-tracking device consistently showed the same values when the subjects fixated previously monitored locations. Calibration checks made throughout the experiment showed no deviation in monitor accuracy.

\section{Procedure}

At the beginning of their session, each subject was familiarized with all 26 letters of the character set used in the experiment. The eye-tracking equipment was then calibrated. The subjects were informed that the eye-tracking equipment would monitor their fixations throughout the experiment and that each stimulus would be available for presentation only when they were fixating centrally. The subjects were told that, to help them fixate centrally, a smail pulsating fixation point would be shown before each trial at the required (central) point of fixation. The pulse rate of this point would initially be low and would remain so until they had steadily fixated this point for I sec, at which time the pulse rate would increase and pressing a key on the keyboard would initiate the next stimulus display. It was stressed that, if the subjects shifted their fixation before target presentation took place, target presentation would be immediately inhibited, and the fixation point would resume its lower pulse rate until central fixation again occurred for $1 \mathrm{sec}$, at which time stimulus presentation would again be available.

At the start of each trial, the fixation point appeared at the center of the screen. When the fixation criteria had been met and the subjects pressed a key, the fixation point disappeared, and the following display sequence was immediately initiated: target; mask; 500 -msec blank. Target exposure duration was calculated individually for each subject. Average exposure duration for targets was $62 \mathrm{msec}$, with a standard deviation of $11 \mathrm{msec}$; masks were presented for $50 \mathrm{msec}$. Fixation location was recorded at target onset and offset. Five hundred msec after mask offset, the target and matched alternative were presented, one above the other, and the subjects had to decide which of these two stimuli had actually been presented. To make their choice, the subjects pressed one of two keys to select either the upper or the lower alternative.

\section{RESULTS}

The use of an eye tracker to control fixation location was highly successful and ensured that central fixation occurred on $100 \%$ of the trials. When questioned, the subjects indicated that the change in pulse rate of the fixation point had helped them to fixate centrally and to maintain this fixation. Furthermore, allowing the subjects to initiate each stimulus display ensured that no subjects were taken unaware by sudden or unexpected stimulus presentations when central fixation was taking place. Monitoring the values returned from the eye tracker revealed varying abilities to fixate centrally at the start of each session, although all improved during the practice period. These differences were particularly apparent in the subjects' ability to maintain steady fixation; although most subjects were able to fixate the fixation point accurately, some could only do this fleetingly, whereas others achieved steady fixation with ease. These variations were dramatically reduced during the practice period, and, in any case, the technique we used ensured steady central fixation at stimulus onset. Moreover, after practice, the subjects achieved and maintained steady fixation very shortly after the onset of the fixation point (typically within $0.5 \mathrm{sec}$ ), and examination of the values returned from the eye tracker at the onset and offset of stimulus presentation revealed that fixation location remained central throughout the presentation of each stimulus. However, these individual differences in subjects' ability to maintain central fixation underscore our concern that inadequate controls for ensuring central fixation may provide varying and contradictory data in divided visual field studies of cerebral asymmetry.

The accuracy data were submitted to an analysis of variance with one within-subjects factors, visual hemifield (LVF or RVF). In line with previous research (see, e.g., Bradshaw \& Nettleton, 1983, for a review), a strong RVF advantage was observed $[F(1,14)=20.67, p<.001]$; overall accuracy of report for words presented in the 
RVF was $78 \%$ correct, whereas overall accuracy of report for words presented in the LVF was $72 \%$. However, in contrast to previous experiments that had not adequately ensured central fixation, the RVF advantage obtained in this experiment is likely to reflect more precisely cerebral processing asymmetry.

\section{DISCUSSION}

The technique we have described allows the benefits of using an eye-tracking device to be extended by the provision of feedback about fixation location and control over visual attention. The use of a pulsating fixation point is a simple but effective method of accommodating both influences and makes this technique easy to implement and available for any tachistoscopic task in which an eye tracker is used to control fixation location.

The benefits of providing feedback about fixation location for studies of lateralized targets may also be applied to studies of foveal target perception. For example, many studies of visual word recognition use foveally presented stimuli preceded by a central fixation point that subjects are specifically instructed to fixate. In many cases, precise fixation of this location may not be important and, indeed, may provide an unwanted influence on subjects' perception of information from different parts of word targets. Nevertheless, feedback about fixation location, coupled with control over target presentation, may permit researchers to define more precisely the screen locations fixated when foveal targets are presented.

The use of pulsating fixation points to control visual attention may also have further potential. Although it has been suggested that a tendency to attend more to one visual field than to the other could account for visual field asymmetries (see, e.g., Bryden, 1980), and given subjects' ability to orient attention independently of the line of sight and of eye movements (see, e.g., Hardyck et al., 1985 ), it is vitally important that every attempt is made to ensure that subjects are attending centrally at the time of target presentation. In the technique we have described, this was achieved by using abrupt onsets via a pulsating fixation point that continued to pulsate (at a faster rate) even when the subjects successfully fixated the required fixation location. However, by using a stable fixation point (instead of one that is pulsating) to signal when central fixation is taking place, researchers may relinquish control over visual attention, while maintaining control over fixation location. Such manipulations may help delineate the role played by attention in performance with lateralized targets.

Similar manipulations may also be used to throw light on the role of attention in foveally presented targets, particularly where fixation location within a word is an important experimental variable (see, e.g., Farid \& Grainger, 1996; Nazir, Heller, \& Sussmann, 1992; Nazir, O’Regan, \& Jacobs, 1991; O’Regan \& Jacobs, 1992). For example,
Johnston and McClelland (1974) investigated the perceptibility of target letters in briefly presented words and found that when subjects were instructed to attend to the entire word, recognition of target letters was superior, compared with when subjects were given prior knowledge of the position of the target letter and instructed to attend this position in the word. Although further research is required to fully understand the role of attention in the processes underlying foveal word recognition, the technique described in this paper provides a method by which the focus of attention could be manipulated. In particular, using stable and pulsating fixation points can provide different levels of attentional engagement, while still providing feedback about fixation accuracy and control over the location fixated at target onset.

In summary, researchers can be confident that subjects are fixating centrally at the time of target presentation only if fixation location is objectively monitored by an eye-tracking device that withholds target presentation until central fixation takes place. However, the mere use of eye-tracking equipment does not overcome all the problems associated with ensuring central fixation, and two further influences on central fixation that should be addressed are the provision of feedback and the role of visual attention. The simple method we present for accommodating both these influences promises to increase the benefits offered by eye-tracking devices for divided visual field studies of cerebral processing asymmetry, in particular, and for a range of other paradigms in which precise control over fixation location is required.

\section{REFERENCES}

ANNETT, M. (1967). The binomial distribution of right, mixed and left handed. Quarterly Journal of Experimental Psychology, 19, 327-333.

ANSTIS, S. M. (1974). A chart demonstrating variations in acuity with retinal position. Vision Research, 14, 589-592.

BATT, V., UNDERWOOD, G., \& BRYdEN, M. P. (1995). Inspecting asymmetric presentation of words differing in informational and morphemic structure. Brain \& Language, 49, 202-223.

Beauvillain, C., \& Beauvillain, P. (1995). Calibration of an eyemovement system for use in reading. Behavior Research Methods, Instruments, \& Computers, 27, 331-337.

Berlucchi, G., Tassinari, G., Marzi, C. A., \& Di Stefano, M. (1989). Spatial distribution of the inhibitory effect of peripheral noninformation cues on simple reaction time to non-fixated visual targets. Neuropsychologia, 27, 201-221.

BoLES, D. B. (1983). Hemispheric interaction in visual field asymmetry. Cortex, 19, 99-113.

BoLES, D. B. (1985). The effects of display and report order asymmetries on lateralized word recognition. Brain \& Language, 26, 106-116.

Bradshaw, J. L., \& Nettleton, N. C. (1983). Human cerebral asymmetry. Englewood Cliffs, NJ: Prentice-Hall.

BRIIHL, D., \& INHOFF, A. W. (1995). Integrating information across fixations during reading: The use of orthographic bodies and of exterior letters. Journal of Experimental Psychology: Human Perception \& Performance, 21, 55-67.

Brindley, G. S., \& Merton, P. A. (1960). The absence of position sense in the human eye. Journal of Physiology, 153, 127-130.

Bryden, M. P. (1980). Attentional factors in the detection of hemispheric asymmetries. In G. Underwood (Ed.), Strategies of information processing (pp. 571-582). New York: Academic Press. 
Bunt, A. H., \& MinckLER, D. S. (1977). Foveal sparing: New anatomical evidence for bilateral representation of the central retina. $\mathrm{Ar}$ chives of Ophthalmology, 95, 1445-1447.

Carroll, J. B., Davies, P., \& Richman, B. (1971). The American Heritage word frequency book. Boston: Houghton-Mifflin.

Carter, G. L., \& Kunsbourne, M. (1979). The ontogeny of right cerebral lateralization of spatial mental set. Developmental Psychology, 15, 241-245.

Chiarello, C., Dronkers, N. F., \& Hardyck, C. (1984). Choosing sides on the variability of language lateralization in normal subjects. Neuropsychologia, 22, 363-373.

Christman, S. (1990). Effects of luminance and blur on hemispheric asymmetries in temporal integration. Neuropsychologia, 28, 361-374.

Eden, G. F., SteIn, J. F., WoOd, H. M., \& Wood, F. B. (1994). Differences in eye movements and reading in dyslexic and normal children. Vision Research, 34, 1345-1358.

ENG, T. L., \& Hellige, J. B. (1994). Hemispheric asymmetry for processing unpronounceable and pronounceable letter trigrams. Brain \& Language, 46, 517-555.

EviataR, Z., \& ZAIDEL, E. (1991). The effects of word length and emotionality on hemispheric contribution to lexical decision. Neuropsychologia, 29, 415-428.

FARID, M., \& Grainger, J. (1996). How initial fixation position influences visual word recognition: A comparison of French and Arabic Brain \& Language, 53, 351-368.

Faust, M., Kravetz, S., \& BabKoff, H. (1993). Hemispheric specialization or reading habits: Evidence from lexical decision research with Hebrew words and sentences. Brain \& Language, 44, 254-263.

Findlay, J. M., \& Kapoula, Z. (1992). Scrutinization, spatial attention, and the spatial programming of saccadic eye movements. Quarterly Journal of Experimental Psychology: Human Perception \& Performance, 45, 633-647.

FischeR, B. (1986). The role of attention in the preparation of visually guided eye movements in monkey and man: Visual selective attention [Special issue]. Psychological Research, 48, 251-257.

FisCHER, B., \& BREITMEYER, B. (1987). Mechanisms of visual attention revealed by saccadic eye movements. Neuropsychologia, 25, 73-83.

Groner, R., Groner, M. T., Muller, P., Bischof, W. F., \& Di Lollo, V. (1993). On the confounding effects of phosphor persistence in oscilloscopic displays. Vision Research, 33, 913-917.

Hardyck, C., Chiarello, C., Dronkers, N. F., \& Simpson, G. V. (1985). Orienting attention within the visual fields: How efficient is interhemispheric transfer? Journal of Experimental Psychology: Human Perception \& Performance, 11, 650-666.

Hellige, J. B., \& SERGENT, J. (1986). Role of task factors in visual field asymmetries. Brain \& Cognition, 5, 200-222.

Hellige, J. B., TAYLoR, K. A., \& ENG, L. T. (1989). Interhemispheric interaction when both hemispheres have access to the same stimulus information. Journal of Experimental Psychology: Human Perception \& Performance, 154, 711-722.

Helmholtz, H. von (1925). Treastise on physiological optics (J. P. C. Southall, Ed.). New York: Dover. (Original work published 1866)

HiNEs, D. (1972). Bilateral tachistoscopic recognition of verbal and non-verbal stimuli. Cortex, 8, 315-322.

INHOFF, A. W. (1989). Parafoveal processing of words and saccade computation during eye fixations in reading. Journal of Experimental Psychology: Human Perception \& Performance, 15, 544-555.

JoHnston, J. C. (1978). A test of the sophisticated guessing theory of word perception. Cognitive Psychology, 10, 123-153.

Johnston, J. C., \& McClelland, J. L. (1974). Perception of letters in words: Seek not and ye shall find. Science, 184, 1192-1193.

JONES, B., \& SANTI, A. (1978). Lateral asymmetries in visual perception with and without eye movements. Cortex, 14, 164-168.

JONiDES, J., \& YANTIS, S. (1988). Uniqueness of abrupt visual onset in capturing attention. Perception \& Psychophysics, 43, 346-354.

JORDAN, T. R., \& BEVAN, K. M. (1996). Position-specific masking and the word-letter phenomenon: Reexamining the evidence from the Reicher-Wheeler paradigm. Journal of Experimental Psychology: Human Perception \& Performance, 6, 1416-1433.

JoRDAN, T. [R.], \& MARTIN, C. (1987). The importance of visual angle in word recognition: A "shrinking screen" modification for visual displays. Behavior Research Methods, Instruments, \& Computers, 19, 307-310.

Jordan, T. R., Patching, G. R., \& Milner, A. D. (1998a). Central fixations are inadequately controlled by instructions alone: Implications for studying cerebral asymmetry. Quarterly Journal of Experimental Psychology, 51A, 371-391.

Jordan, T. R., Patching, G. R., \& Milner, A. D. (1998b). Hemispheric specialization, modes of lexical access and perceptual asymmetry: Investigating lateralized word recognition using the Reicher-Wheeler paradigm. Manuscript submitted for publication.

KIM, H. (1996). Qualitative hemispheric differences for processing trigrams. Brain \& Cognition, 30, 205-214.

KimuRA, D. (1961). Cerebral dominance and the perception of verbal stimuli. Canadian Journal of Psychology, 23, 445-458.

Kitterle, F. L., Christman, S., \& Conesa, J. (1993). Hemispheric differences in the interference among components of compound gratings. Perception \& Psychophysics, 54, 785-793.

Koenig, O., Wetzel, C., \& Caramazza, A. (1992). Evidence for different types of lexical representation in the cerebral hemispheres. Cognitive Neuropsychology, 9, 33-45.

LUH, K. E., \& LEVY, J. (1995). Interhemispheric cooperation: Left is left and right is right, but sometimes the twain shall meet. Journal of Experimental Psychology: Human Perception \& Performance, 21, $1243-1258$.

Lukatela, G., Carello, C., Savic, M., \& Turvey, M. T. (1986). Hemispheric asymmetries in phonological processing. Neuropsychologia, 24, 341-350.

Mackeben, M., \& Nakayama, K. (1993). Express attentional shifts. Vision Research, 33, 85-90.

Maddess, R. J., Rosenblood, L. K., \& Goldwater, B. C. (1973). An improved technique for monitoring fixation in tachistoscopic tasks. Quarterly Journal of Experimental Psychology, 25, 398-403.

MCKeEver, W. F., \& Huling, M. D. (1971). Lateral dominance in tachistoscopic word recognition performance obtained with simultaneous bilateral input. Neuropsychologia, 9, 15-20.

Mohr, B., Pulvermüller, F., \& Zaidel, E. (1994). Lexical decision after left, right and bilateral presentation of function words, content words and non-words: Evidence for interhemispheric interaction. Neuropsychologia, 32, 105-123.

Nazir, T. A., Heller, D., \& SusSmann, C. (1992). Letter visibility and word recognition: The optimal viewing position in printed words. Perception \& Psychophysics, 52, 315-328.

Nazir, T. A., O'Regan, J. K., \& JACOBS, A. M. (1991). On words and their letters. Bulletin of the Psychonomic Society, 29, 171-174.

Nicholls, M. E. R., \& ATKinson, J. (1993). Hemispheric asymmetries for an inspection time task: A general left hemisphere temporal advantage? Neuropsychologia, 31, 1181-1190.

O'Regan, J. K., \& JacoBs, A. M. (1992). Optimal viewing position effects in word recognition and reading: A challenge to current theory. Journal of Experimental Psychology: Human Perception \& Performance, 18, 185-197.

Patching, G. R., Jordan, T. R., \& Milner, A. D. (1998). Do different retinal eccentricities affect the relative perceptibility of letters in words? Manuscript submitted for publication.

RAYNER, K., \& INHOFF, A. W. (1981). Control of eye movements during reading. In B. L. Zuber (Ed.), Models of oculomotor behaviour and control. Boca Raton, FL: CRC Press.

Rercher, G. M. (1969). Perceptual recognition as a function of meaningfulness of stimulus material. Journal of Experimental Psychology, 28, 115-121

Reuter-Lorenz, P. A.. \& Baynes, K. (1992). Modes of lexical access in the callosotomized brain. Journal of Cognitive Neuroscience, $\mathbf{4}$, 155-164.

Reuter-Lorenz, P. A., Hughes, H. C., \& Fendrich, R. (1991). The reduction of saccadic latency by prior offset of the fixation point: An analysis of the gap effect. Perception \& Psychophysics, 49, 167-175.

SChmuller, J., \& GoOdman, R. (1979). Bilateral tachistoscopic perception, handedness and laterality, Brain \& Language, 8, 81-91.

SChwartz, S., Montagner, S., \& KirSner, K. (1987). Are there different methods of access for words presented in the left and right visual fields? Brain \& Language, 31, 301-307. 
Sheliga, B. M., Kuznetsov, Y. B., \& Shul'govskiI, V. V. (1991). Disengagement of attention as a stage in saccadic eye movement programming. Sensory-Systems, 5, 103-108.

STEINMAN, R. M. (1977). Role of eye movements in maintaining a phenomenally clear and stable world. In R. A. Monty \& J. W. Senders (Eds.), Eye movements and psychological processes (pp. 121-154). Hillsdale, NJ: Erlbaum.

TERRACE, H. S. (1959). The effects of retinal locus and attention on the perception of words. Journal of Experimental Psychology, 58, 382-385.

Tramer, O., Butler, B. E., \& Mewhort, D. K. (1985). Evidence for scanning with unilateral visual presentation of letters. Brain \& Language, 25, 1-18.

WAGNER, N. M., \& HARRIS, L. J. (1994). Effects of typeface characteristics on visual field asymmetries for letter identification in children and adults. Brain \& Language, 46, 41-58.

Wolford, G., MarchaK, F., \& Hughes, H. (1988). Practice effects in backward masking. Journal of Experimental Psychology: Human Perception \& Performance, 14, 101-112.
WUNDT, W. (1912). Introduction to psychology (R. Pinter, Trans.). London: George Allen.

YANTIS, S., \& Jonides, J. (1984). Abrupt visual onsets and selective attention: Evidence from visual search. Journal of Experimental Psychology: Human Perception \& Performance, 10, 601-621.

Young, A. W., \& Ellis, A. W. (1985). Different methods of lexical access for words presented in the left and right visual hemifields. Brain \& Language, 24, 326-358

\section{NOTE}

1. We found that a second was a reasonable time to ask subjects to fixate centrally and had the added advantage of ensuring maintained steady fixation rather than a fleeting glance (see, e.g., Hellige \& Sergent, 1986).

(Manuscript received December 2, 1996; revision accepted for publication August 21, 1997.) 